\title{
ORIGINAL ARTICLE CARDIOVASCULAR INVOLVEMENT AND MORTALITY WITH NEW COVID-19 VARIANTS
}

\author{
Muharrem Said Cosgun ${ }^{1}$ \\ ${ }^{1}$ Mengucek Gazi Education and Research Hospital, Medical Faculty, Erzincan Binali Yildirim University, Erzincan, Turkey
}

Objectives: The presence of cardiac involvement is accepted as an indicator of morbidity and mortality in Coronavirus disease 2019 (COVID-19) patients. Therefore, this study investigates data on cardiovascular involvement and clinical outcomes between the first wave with wild virus and mutation-dominant second wave of the COVID-19 outbreak.

Methodology: This was a single centre, retrospective study using and the data was collected from confirmed COVID-19 patients. Patients' demographic and clinical characteristics, cardiovascular involvement, and the factors associated with mortality were analysed. All these data were compared between first (wild virus) and second-wave (mutant viruses) patients.

Results: The study included 476 positive inpatients confirmed by a real-time polymerase chain reaction. Although the length of hospital stay was similar, the duration of intensive care units (ICUs) was longer in the second wave $(6.3 \pm 3.2$ vs. $7.5 \pm 3.5 ; \mathrm{p}=0.020)$. The rate of severe illness ( 12.9 vs. $20.3 \%$; $p=0.037$ ) and critical illness referral to ICUs ( 4.3 vs. $9.7 \%$; $p=0.031$ ) was higher in the second wave than in the first. In addition, the incidence of myocardial damage was significantly higher in the second wave ( 4.3 vs. $10.7 \%$; $\mathrm{p}=0.046)$.

Conclusion: In the present study, myocardial injury, development of critical illness, and referral to the ICUs increased in correlation with the disease severity in the second wave compared to the first. Variant viruses and possibly the burden of the crowd on healthcare contribute to this situation. Therefore, epidemiological data are required to guide situational awareness as long as the pandemic remains.

Keywords: Coronavirus disease 2019, mutation, variant, cardiac involvement, mortality

Citation: Cosgun MS. Cardiovascular Involvement and Mortality with New COVID-19 Variants. Pak Heart J. 2021;54(03):244-248. DOI: https://doi.org/10.47144/phj.v54i3.2084

\section{INTRODUCTION}

The emergence of the new coronavirus called severe acute respiratory syndrome coronavirus 2 (SARS$\mathrm{CoV}-2$ ) has placed intense pressure on the healthcare community worldwide. ${ }^{1}$ The Republic of Turkey Ministry of Health has established an advisory board on coronavirus research and compiled national recommendations on diagnosing, treating, and controlling the disease in a document; its first version was published in May 2020. Consequently, the recommendations and algorithms in this guide, which are frequently updated according to the course of the outbreak, have formed the basis of most efforts for the diagnosis, treatment, and follow-up of patients with the coronavirus disease 2019 (COVID-19) in Turkey. ${ }^{2}$ We arranged our treatment in line with these documents.

Despite the vaccination, strict restrictions, and the lockdown, the outbreak continues more than one year rapidly due to new mutations, thus negatively affecting World. ${ }^{3}$ The first wave caused by the wild virus in our country was in December 2020, and the second wave due to mutant viruses occurred in April $2021{ }^{4}$ As in many states, the increasing number of patients in our state has overwhelmed the capacity of healthcare services, but despite the various challenges, all patients still have access to the care they need. This study investigated clinical outcome differences such as cardiovascular involvement and mortality due to varying variants between the first and second waves of the outbreak.

\section{METHODOLOGY}

This was a single center, retrospective study and the data was collected from consecutive confirmed COVID-19 patients. The first peak of the epidemic in our country was in December 2020, and the second peak was in April 2021.4 The study population consisted of patients hospitalized for COVID-19 in the first half of December 2020 and the first half of April 2021 and included 476 patients, 186 in the first wave and 290 in the second wave. All patients were monitored and treated in the inpatient clinics, including the intensive care units (ICUs). Patients under 18 years were excluded from the study. The diagnosis of the patients was confirmed by real-time polymerase chain reaction (RT-PCR). According to the "Management of Severe Pneumonia, ARDS, Sepsis and Septic Shock" published by the Republic of Turkey Ministry of Health, patients were divided 
into three clinical groups. ${ }^{5}$ Mild illness presents with features such as fever, muscle/joint pain, cough, sore throat, and nasal congestion, with or without mild pneumonia together with a respiratory rate $<30 /$ min and an $\mathrm{O} 2$ saturation above $90 \%$ while breathing room air. Severe illness is defined with widespread findings signs of pneumonia on computed tomography (CT). Critical illness defines the requirement of the ICUs. Cardiovascular involvement was considered a myocardial injury (elevation of cardiac troponin I above 99th percentile upper reference limit), arrhythmia, and thrombosis development. Demographic data, risk factors, clinical characteristics, radiological and laboratory findings of the patients were recorded.

Our study was designed in accordance with the Helsinki Declaration of 1975, as revised in 1983. Ethics committee approval was received from the institutional ethics committee (date: 07/07/2020, meeting no: 07 and protocol number: 06) and the Republic of Turkey Ministry of Health. Patients have given their informed consent for participation in the research study.

Categorical variables were compared with the chisquare test and shown as percentages (\%). Continuous variables were shown as mean \pm standard deviation if normally distributed and median (1st-3rd quartiles) if not normally distributed. For the analysis of continuous variables, their distribution was evaluated using the One-Sample Kolmogorov-Smirnov test. The t-test was used in the continuous variables between the two groups normally distributed, and the MannWhitney U test was used if they were not normally distributed. Statistical significance value was considered as $\mathrm{p} \leq 0.05$. All data obtained were transferred to SPSS version 22 and analyzed (IBM, SPSS Statistics, USA).

\section{RESULTS}

The mean age was significantly higher in the second wave; it was $51 \pm 11$ and $53 \pm 10$ in the first and second waves, respectively ( $\mathrm{p}=0.042$ ). Gender distribution, smoking habits, and comorbid disorders were similar in both waves. The most common comorbid diseases were hypertension and diabetes (Table 1).

The clinical characteristics of the patients are shown in Table 2. The most common symptoms on admission were cough and fever in both waves. Upper respiratory tract symptoms such as cough (61.8 vs. $52.4 \%$; $\mathrm{p}=0.043$ ), anosmia-ageusia ( 33.9 vs. $25.2 \%$; $\mathrm{p}=0.040$ ), and postnasal-drip ( 24.2 vs. $15.9 \%$; $=0.024)$ were significantly more common in the first wave. On the other hand, systemic symptoms such as fever (44.6 vs. $54.5 \% ; \mathrm{p}=0.036)$ and shortness of breath (19.0 vs. $27.2 \% ; \mathrm{p}=0.041$ ) were significantly more common in the second wave. Other symptoms were similar between groups.

Table 1: Demographic characteristics of the patients

\begin{tabular}{|l|c|c|c|}
\hline & $\begin{array}{c}\text { First wave } \\
(\mathbf{n = 1 8 6})\end{array}$ & $\begin{array}{c}\text { Second wave } \\
(\mathbf{n = 2 9 0})\end{array}$ & $\mathbf{p}$ \\
\hline Age (years) & $51 \pm 11$ & $53 \pm 10$ & 0.042 \\
\hline Gender, male & $92(49.5)$ & $135(46.6)$ & 0.535 \\
\hline Active smoker & $39^{*}(21.0)$ & $54^{\#}(18.6)$ & 0.529 \\
\hline Comorbid diseases & $78(41.9)$ & $120(41.4)$ & 0.904 \\
\hline Hypertension & $54(29.0)$ & $79(27.2)$ & 0.671 \\
\hline Diabetes mellitus & $39(21.0)$ & $58(20.0)$ & 0.798 \\
\hline $\begin{array}{l}\text { Coronary artery } \\
\text { disease }\end{array}$ & $32(17.2)$ & $48(16.6)$ & 0.853 \\
\hline $\begin{array}{l}\text { Chronic pulmonary } \\
\text { disease }\end{array}$ & $29(15.6)$ & $44(15.2)$ & 0.901 \\
\hline
\end{tabular}

Lengths of hospital stay were similar in both waves, but ICU stays periods were significantly longer in the second wave than the first $(6.3 \pm 3.2$ vs. $7.3 \pm 3.5$; $\mathrm{p}=0.020$ ). While the mild illness rate decreased in the second wave, severe illness rates (12.9 vs. 20.3\%; $\mathrm{p}=0.037)$ and critical illness were referred to ICUs (4.3 vs. $9.7 \% ; \mathrm{p}=0.031)$ increased.

Table 2: Clinical characteristics of the patients

\begin{tabular}{|c|c|c|c|}
\hline & $\begin{array}{c}\text { First wave } \\
(n=186)\end{array}$ & $\begin{array}{c}\text { Second wave } \\
(n=290)\end{array}$ & $\mathbf{p}$ \\
\hline \multicolumn{4}{|l|}{ Symptoms } \\
\hline Cough & $115(61.8)$ & $152(52.4)$ & 0.043 \\
\hline Fever & $83(44.6)$ & $158(54.5)$ & 0.036 \\
\hline Anosmia-ageusia & $63(33.9)$ & $73(25.2)$ & 0.040 \\
\hline Lassitude-fatigue & $58(31.2)$ & $97(33.4)$ & 0.607 \\
\hline Appetite loss & $52(28.0)$ & $85(29.3)$ & 0.750 \\
\hline Post-nasal drip & $45(24.2)$ & $46(15.9)$ & 0.024 \\
\hline Shortness of breath & $35(19.0)$ & $79(27.2)$ & 0.041 \\
\hline \multicolumn{4}{|l|}{ Length of stay } \\
\hline Hospital stay & $5.9 \pm 2.4$ & $6.2 \pm 2.8$ & 0.255 \\
\hline ICUs $^{*}$ stay & $6.3 \pm 3.2$ & $7.5 \pm 3.5$ & 0.020 \\
\hline \multicolumn{4}{|l|}{ Disease severity } \\
\hline Severe & $24(12.9)$ & $59(20.3)$ & 0.037 \\
\hline Critical $^{\#}$ & $8(4.3)$ & $28(9.7)$ & 0.031 \\
\hline $\begin{array}{l}\text { Cardiovascular } \\
\text { involvement }\end{array}$ & $13(7.0)$ & $34(11.7)$ & 0.233 \\
\hline Myocardial injury & $8(4.3)$ & $31(10.7)$ & 0.046 \\
\hline Arrhythmia & $5(2.7)$ & $4(1.4)$ & 0.581 \\
\hline Thrombosis & $2(1.1)$ & $2(1.0)$ & 0.994 \\
\hline \multicolumn{4}{|l|}{ Mortality } \\
\hline Overall mortality & $4(2.2)$ & $13(4.5)$ & 0.406 \\
\hline $\begin{array}{l}\text { Cardiovascular } \\
\text { involvement }\end{array}$ & $2(15.4)$ & $10(29.4)$ & 0.324 \\
\hline ICUs $^{*}$ & $3(37.5)$ & $13(46.4)$ & 0.654 \\
\hline
\end{tabular}

* Intensive care units

\# Refferal to intensive care units 
Cardiovascular involvement was similar between the groups; although arrhythmia was slightly reduced in the second wave (2.7 vs. $1.4 \%)$, myocardial injury rates were significantly higher $(4.3$ vs. $10.7 \%$; $=$ 0.046). Thrombosis rates were similar in both waves. Overall mortality (2.2 vs. $4.5 \%)$, mortality in patients with cardiovascular involvement (15.4 vs. $29.4 \%$ ), and mortality in the ICUs (37.5 vs. $46.4 \%$ ) were higher in the second wave but not statistically meaningful.

In the laboratory findings on admission, white blood cell, platelet, and lactate dehydrogenase values were similar. C reactive protein $(10.3$ vs. $30.0 ; \mathrm{p}<0.001)$, procalcitonin $(0.13$ vs. $0.20 ; \mathrm{p}<0.001)$, and $\mathrm{D}$-dimer (591 vs. 727; $\mathrm{p}=0.001$ ) levels were significantly higher in the second wave. Likewise, lymphopenia was more common in the second wave ( 1380 vs. $1100 ; p=0.001)$. CT examination showed that the diffuse spread was significantly higher in the second wave $(22.0 \%$ vs. $31.0 \% ; \mathrm{p}=0.032$ ) (Table 3).

Table 3: Laboratory results and computed tomography findings of the patients

\begin{tabular}{|c|c|c|c|}
\hline & $\begin{array}{c}\text { First wave } \\
(n=186)\end{array}$ & $\begin{array}{c}\text { Second wave } \\
(n=290)\end{array}$ & $\mathbf{P}$ \\
\hline \multicolumn{4}{|c|}{ Laboratory parameters } \\
\hline $\begin{array}{l}\text { White blood cell } \\
\text { count, } \times 10^{9} / \mathrm{L}\end{array}$ & $\begin{array}{c}3.75 \\
(1.3-14.69)\end{array}$ & $\begin{array}{c}4.05 \\
(0.29-16.02) \\
\end{array}$ & 0.575 \\
\hline $\begin{array}{l}\text { Lymphocyte count, } \\
\times 10^{9} / \mathrm{L}\end{array}$ & $\begin{array}{c}1380 \\
(120-5300)\end{array}$ & $\begin{array}{c}1100 \\
(180-2290)\end{array}$ & 0.001 \\
\hline $\begin{array}{l}\text { Platelet count, } \\
\times 10^{9} / \mathrm{L}\end{array}$ & $\begin{array}{c}231 \\
(22.2-976)\end{array}$ & $\begin{array}{c}222 \\
(9-466)\end{array}$ & 0.100 \\
\hline $\begin{array}{l}\mathrm{C} \text { reactive protein, } \\
\mathrm{mg} / \mathrm{L}\end{array}$ & $\begin{array}{c}10.3 \\
(5.8-148) \\
\end{array}$ & $\begin{array}{c}30.0 \\
(10-252) \\
\end{array}$ & $<0.001$ \\
\hline Procalcitonin, $\mu \mathrm{g} / \mathrm{L}$ & $\begin{array}{c}0.13 \\
(0-3.8)\end{array}$ & $\begin{array}{c}0.20 \\
(0-4.4)\end{array}$ & $<0.001$ \\
\hline D-dimer, $\mu \mathrm{g} / \mathrm{L}$ & $\begin{array}{c}591 \\
(440-7820) \\
\end{array}$ & $\begin{array}{c}727 \\
(572-14930) \\
\end{array}$ & 0.001 \\
\hline $\begin{array}{l}\text { Lactate } \\
\text { dehydrogenase, } \\
\text { U/L }\end{array}$ & $\begin{array}{c}242 \\
(0-2.539)\end{array}$ & $\begin{array}{c}250 \\
(100-788)\end{array}$ & 0.103 \\
\hline \multicolumn{4}{|c|}{ Radiological distribution } \\
\hline Peripheral & $118(63.4)$ & $170(58.6)$ & 0.294 \\
\hline Central & $27(14.5)$ & $30(10.3)$ & 0.171 \\
\hline Diffuse & $41(22.0)$ & $90(31.0)$ & 0.032 \\
\hline
\end{tabular}

The rates of low-molecular-weight heparin treatment were similar in both waves. In comparison, the use of oseltamivir was high in the first wave (57.0 vs. $25.5 \%$; $\mathrm{p}<0.001$ ), this ratio was in favor of favipiravir in the second wave $(37.6$ vs. $69.3 \% ; \quad \mathrm{p}<0.001)$. Hydroxychloroquine usage was significantly low at the second wave (49.7 vs. $23.4 \%$; $<<0.001$ ). Antibiotic (67.6 vs. $76.6 \% ; \mathrm{p}=0.026)$ and corticosteroid ( 22.2 vs. $32.8 \% ; \mathrm{p}=0.037)$ use were higher in the second wave (Table 4).
Table 4: Treatment of the patients

\begin{tabular}{|l|c|c|c|}
\hline & $\begin{array}{c}\text { First } \\
\text { wave } \\
(\mathbf{n = 1 8 6})\end{array}$ & $\begin{array}{c}\text { Second } \\
\text { wave } \\
(\mathbf{n = 2 9 0})\end{array}$ & P \\
\hline Oseltamivir & $106(57.0)$ & $74(25.5)$ & $<0.001$ \\
\hline Favipiravir & $70(37.6)$ & $201(69.3)$ & $<0.001$ \\
\hline $\begin{array}{l}\text { Low-molecular- } \\
\text { weight heparin }\end{array}$ & $167(89.8)$ & $262(90.3)$ & 0.842 \\
\hline $\begin{array}{l}\text { Hydroxychloroq } \\
\text { uine }\end{array}$ & $92(49.7)$ & $68(23.4)$ & $<0.001$ \\
\hline Antibiotics & $125(67.6)$ & $222(76.6)$ & 0.026 \\
\hline Corticosteroids & $41(22.2)$ & $95(32.8)$ & 0.037 \\
\hline
\end{tabular}

\section{DISCUSSION}

Our study showed a significant increase in myocardial injury rates in the second wave, which developed due to mutations, compared to the first wave. In addition, with the increase in the severity of the disease, the need for ICUs and the length of stay in ICUs increased.

The COVID-19 outbreak varies between countries. The possible reasons for this variation include demographic and socio-cultural structures, transportation at national and international levels, healthcare capacity, ease of healthcare access, the versatility of healthcare systems, and the extent and timing of the pandemic control strategies directed by governments. Epidemiological data are needed to guide situational awareness and intervention strategies throughout this pandemic. This article presents the first data on cardiovascular involvement in Turkey's second wave of the COVID-19 outbreak.

In the second wave, more patients were followed up on an outpatient basis due to limitations in hospital capacity and many patients. In the second wave, referrals to ICUs increased due to the more severe course of the disease.

The average age of the second wave was higher, as young people who were more socially active in the first wave were infected. ${ }^{6}$ The literature includes papers reporting sex-related differences in terms of the prevalence and severity of COVID-19 infection. ${ }^{7}$ According to a study from China, the prevalence in males is higher because the expression of the angiotensin-converting enzyme 2 is more dominant in Asian men, and smoking is more common in men than in women $(50.5 \%$ vs. $2.6 \%){ }^{8}$ However, in the present study, the male-to-female ratio was 1:1.09, and the smoking rate of males was only two times that of females. The equal distribution of gender prevalence may be due to the fact that the men in this study smoke less and the women smoke more than their counterparts in previous studies. 
Studies have shown that anosmia, an upper respiratory tract symptom, is associated with a good prognosis in patients with COVID-19.9, 10 In the present study, nonsystemic symptoms, such as cough, anosmiaageusia, and postnasal drip, were more common in the first wave. In contrast, systemic symptoms, such as fever and shortness of breath, were more common in the second wave. These situations indicate that the disease was less severe in the first wave, although comorbid disorders are at a similar rate. In addition, the more extended periods of stay in ICUs in the second wave support this inference.

In a report by the Chinese Center for Disease Control and Prevention on 44,672 patients, the disease followed mild, severe, and critical courses in $81 \%$, $14 \%$, and $5 \%$, respectively, of these cases. ${ }^{11,12}$ In our study, there was a similar illness severity distribution in the first wave. However, due to the increase in the severity of the disease in the second wave, the rates of severe illness and critical patients referred to ICUs were significantly higher.

In COVID-19, cardiac injury and increased mortality are related. A study conducted in China found a significant increase in mortality in patients with cardiac injury compared with those without cardiac injury (51.2\% and $4.5 \%$, respectively). ${ }^{13}$ In the current study, mortality rates of $15.4 \%$ in the first wave and $29.4 \%$ in the second wave were seen in patients with cardiovascular involvement. Troponin levels exceeding the 99th percentile at the upper reference limit are observed in $8 \%$ to $12 \%$ of patients with COVID-19. ${ }^{14}$ A study in 138 Chinese patients with COVID-19 reported a $7.2 \%$ incidence of acute cardiac injury and $16.7 \%$ incidence of arrhythmia. ${ }^{15}$ In our study, while the rate of myocardial damage was low in the first wave, it was considerably higher in the second (4.3\% vs. $10.7 \%$, respectively). However, arrhythmia was less common, probably due to the severe decrease in hydroxychloroquine use in the second wave. ${ }^{16}$

In another large-scale study, the overall mortality rate was $2.3 \%$; about $5 \%$ of the patients had a severe course with complications, including respiratory failure, septic shock, and multiorgan failure, with mortality as high as $50 \% .{ }^{17}$ Similarly, in our study, the overall mortality rate was $2.2 \%$ in the first wave. The critical illness group, comprising $4.3 \%$ of the patients, had a mortality rate of $37.5 \%$ in the first wave. However, overall mortality and ICU ( $9.7 \%$ of patients) mortality rates were higher in the second wave $(4.5 \%$ and $46.4 \%$, respectively). Laboratory results (elevated C reactive protein, procalcitonin, and D-dimer levels, and lymphopenia) and radiological findings (diffuse spread) indicate high illness severity in the second wave. More frequent use of antibiotics and corticosteroids also supports this situation. ${ }^{18}$

Limitations of the study: The most important limitation of the study was that it was conducted in a single center.

\section{CONCLUSION}

In the present study, myocardial injury, referral to ICUs rates, and ICUs stay days increased in correlation with the increase in disease severity in the second wave compared with the first. This situation is probably contributing to the increased burden on healthcare workers and the increase in the number of patients. This disease process also suggests that the pathogenicity of the virus may have increased in the second wave compared with the first.

\section{AUTHORS' CONTRIBUTION}

MSC: Concept and design, data acquisition, interpretation, drafting, final approval, and agree to be accountable for all aspects of the work.

Conflict of interest: Authors declared no conflict of interest.

\section{REFERENCES}

1. Sharma A, Tiwari S, Deb MK, Marty JL. Severe acute respiratory syndrome coronavirus-2 (SARS-CoV-2): a global pandemic and treatment strategies. Int J Antimicrob Agents. 2020;56(2):106054.

2. Republic of Turkey Ministry Of Health, General Directorate of Public Health, Coronavirus Scientific Advisory Board, COVID19 (SARS-CoV-2 INFECTION) (Study of Scientific Board), General Information, Epidemiology and Diagnosis. 2020. https://hsgm.saglik.gov.tr/depo/covid19/Ingilizce/Rehber/COVI D-

19_Rehberi_Genel_bilgiler_epidemiyoloji_ve_tani_8.06.2020_ eng.pdf (Website).

3. Baric RS. Emergence of a Highly Fit SARS-CoV-2 Variant. N Engl J Med. 2020;383(27):2684-6.

4. World Health Organization, https://covid19.who.int/region/euro/country/tr (Website).

5. Republic of Turkey Ministry Of Health, General Directorate of Public Health, Coronavirus Scientific Advisory Board, COVID19 (SARS-CoV-2 INFECTION) (Study of Scientific Board), Management of Severe Pneumonia, ARDS, Sepsis and Septic Shock. 2020 https://hsgm.saglik.gov.tr/depo/covid19/Ingilizce/Rehber/COVI D-

19_Rehberi_Ar_pnomoni_ARDS_sepsis_ve_septik_ok_yoneti mi_8.06.2020_eng.pdf (Website).

6. Venkatesan P. The changing demographics of COVID-19. Lancet Respir Med. 2020;8(12):e95.

7. Alhazzani W, Møller MH, Arabi YM, Loeb M, Gong MN, Fan E, et al. Surviving Sepsis Campaign: guidelines on the management of critically ill adults with Coronavirus Disease 2019 (COVID19). Intensive Care Med. 2020;46(5):854-87.

8. Cai H. Sex difference and smoking predisposition in patients with COVID-19. Lancet Respir Med. 2020 Apr;8(4):e20. doi: 10.1016/S2213-2600(20)30117-X. Epub 2020 Mar 11. Erratum in: Lancet Respir Med. 2020;8(4):e26.

9. Mendonça CV, Mendes Neto JA, Suzuki FA, Orth MS, Machado Neto H, Nacif SR. Olfactory dysfunction in COVID-19: a marker 
of good prognosis? Braz J Otorhinolaryngol. 2021. DOI: https://dx.doi.org/10.1016\%2Fj.bjorl.2020.12.002

10. Sanli DET, Altundag A, Kandemirli SG, Yildirim D, Sanli AN, Saatci O, et al. Relationship between disease severity and serum IL-6 levels in COVID-19 anosmia. Am J Otolaryngol. 2021;42:102796

11. Li Q, Guan X, Wu P, Wang X, Zhou L, Tong Y, et al. Early Transmission Dynamics in Wuhan, China, of Novel CoronavirusInfected Pneumonia. N Engl J Med. 2020;382(13):1199-207.

12. $\mathrm{Wu} \mathrm{Z,} \mathrm{McGoogan} \mathrm{JM.} \mathrm{Characteristics} \mathrm{of} \mathrm{and} \mathrm{Important} \mathrm{Lessons}$ From the Coronavirus Disease 2019 (COVID-19) Outbreak in China: Summary of a Report of 72314 Cases From the Chinese Center for Disease Control and Prevention. JAMA. 2020;323(13):1239-42.

13. Siddiqi HK, Mehra MR. COVID-19 illness in native and immunosuppressed states: A clinical-therapeutic staging proposal. J Heart Lung Transplant. 2020;39(5):405-7.
14. Shi S, Qin M, Shen B, Cai Y, Liu T, Yang F, et al. Association of Cardiac Injury With Mortality in Hospitalized Patients With COVID-19 in Wuhan, China. JAMA Cardiol. 2020;5(7):802-10.

15. Lippi G, Plebani M. Procalcitonin in patients with severe coronavirus disease 2019 (COVID-19): A meta-analysis. Clin Chim Acta. 2020;505:190-1.

16. Wang D, Hu B, Hu C, Zhu F, Liu X, Zhang J, et al. Clinical Characteristics of 138 Hospitalized Patients With 2019 Novel Coronavirus-Infected Pneumonia in Wuhan, China. JAMA. 2020 Mar 17;323(11):1061-9.

17. Mai F, Del Pinto R, Ferri C. COVID-19 and cardiovascular diseases. J Cardiol. 2020;76(5):453-8.

18. Gallo Marin B, Aghagoli G, Lavine K, Yang L, Siff EJ, Chiang SS, $\mathrm{S}$ et al. Predictors of COVID-19 severity: A literature review. Rev Med Virol. 2021;31(1):1-10.

\section{Address for Correspondence:}

Dr. Muharrem Said Cosgun, Assistant Professor, Erzincan Binali Yildirim University, Medical Faculty, Department of Cardiology, Erzincan, Turkey.

Email: drsaidcosgun2009@ hotmail.com 